\title{
Interactive comment on "Assessment and Projection of Water Budget over Western Canada using Convection Permitting WRF Simulations" by Sopan Kurkute et al.
}

\section{Anonymous Referee \#2}

Received and published: 4 February 2020

This study set up a high-resolution convection-permitting (CP) Weather Research and Forecast (WRF) model and applied this model to two large basins in Canada to evaluate the performance by comparing the simulated surface water budget and atmospheric moisture balance with three reanalysis datasets. Results show that Highresolution WRF in both river basins has much lower residual term of water budget compared with the reanalysis data. Additionally, the historical and future surface water budget and atmospheric moisture balance in study basins were investigated by the high-resolution WRF model. Admittedly, authors did a lot of work. Unfortunately, this manuscript read like a technical report not a paper due to lack of a scientific question. Even as a technical report, the organization of this manuscript still needs a substan-

Printer-friendly version

Discussion paper 
tial improvement and many details also needs to be supplemented (see below specific comments). Therefore, I am afraid that I can't recommend publication of the manuscript in HESS, at least in this version.

Specific comments: 1. P6 Lines 4-6 ("This simulation was forced ...... (Dee et al., 2011))."), there are three reanalysis datasets collected in this study. Why do we only use ERA-Interim to force the WRF model? 2. P6 Lines 6-7 ("Tests showed that ...... and the WRF domain"), this sentence reads abrupt. How to understand it? What are the tests? Why do we need the tests? Please provide more details for broader audiences. 3. P6 Equation (1), this equation is confused. Does "ERA-Interim" represent one variable or two? 4. P7 Lines 5-7 ("Reanalysis products ..... play important roles"), this sentence is too long to understand. Please rewrite it. 5. P7 section 2.3, why do we need this section? No efficient information is provided. After reading this section, I still don't know how to evaluate the WRF simulation in this study. 6. P7 Lines 16-17 ("The sparse availability ..... (Mesinger et al., 2006)."), there are two "over Canada" in this sentence and please delete the redundant one. 7. P9-10, "Q" in this study represents two variables (i.e., runoff and the vertically integrated moisture flux). It is very confusing and please revise. 8. Fig.2-3, what do the "EVAP", and "APCP" represent? They aren't described in the text. 9. Fig. 6, what does the "MFLUX" mean? It isn't also described in the text. 10. There are lots of "WRF-CTL" and "WRF-PGW" in this manuscript. What are the meanings of them? 11. P26 Lines 15-16 ("For the surface water budget ..... reanalysis datasets"), Even the high-resolution WRF has a significantly lower residual than the reanalysis datasets, does it mean the performance of WRF on simulating individual variable (e.g., runoff or evapotranspiration) is better than the reanalysis datasets? Or does it mean the simulated individual variable is closer to the real value. If not, how do we trust the following analysis?

Printer-friendly version

Discussion paper

Interactive comment on Hydrol. Earth Syst. Sci. Discuss., https://doi.org/10.5194/hess-2019522, 2019.

Interactive

comment 